Melo L.A.P., Lima V.F.C., Melo R.S.S. (2017). "Value Stream Mapping: a Case Study in Structural Masonry." In: LC3 2017 Volume II - Proceedings of the 25th Annual Conference of the International Group for Lean Construction (IGLC), Walsh, K., Sacks, R., Brilakis, I. (eds.), Heraklion, Greece, pp. 755-762. DOI:

https://doi.org/10.24928/2017/0167

\title{
VALUE STREAM MAPPING: A CASE STUDY IN STRUCTURAL MASONRY
}

\author{
Luane A. P. Melo ${ }^{1}$ Victor F. C. de Lima ${ }^{2}$ and Reymard Savio S. de Melo ${ }^{3}$
}

\begin{abstract}
There is a growing interest in the Lean Thinking (LT) principles due to the high levels of waste in construction. Value Stream Mapping (VSM) is as an important tool for a systematic implementation of the LT. Few studies have addressed the application of VSM for improvements related to the execution of structural masonry, therefore this article presents an exploratory case study that aims to propose improvements for this process. Data was collected in a residential project, where the execution of structural masonry is the activity of greatest impact in the budget and schedule. From field observations, interviews and analysis of administrative documentation, the VSM of the current state was elaborated and analyzed through the LT. Improvements in the future VSM focused mainly in the elimination of transport and excess (inventory) wastes. A reduction of $45.5 \%$ in cycle time and an increase in Value Aggregation Time (VAT) from 32.45 to $60.55 \%$ is estimated. The VSM provided a systemic view of the value chain of the process, facilitating the identification of wastes, their origin and the proposition of improvements.
\end{abstract}

Keywords: Value Stream Mapping, Structural masonry, Lean Thinking.

\section{INTRODUCTION}

For a long time, Architecture, Engineering and Construction (AEC) industry has dealt with problems related to its low performance in production management, closely linked to the high number of wastes, as a consequence of the application of managerial methods oriented only by conversion activities (Koskela, 1992). There is thereby a growing interest of the academy and industry in the principles and tools of Lean Thinking (LT), referred to as an antidote to waste (Womack and Jones, 1996).

It is important to highlight that LT improvements in AEC industry must be preceded by a change in the way of thinking of those involved in the industry, rather than only applying isolated tools to solve specific problems (Koskela, 1992). In this context, VSM is a way for a systematic implementation of the LT principles, as it drives the improvements throughout the process flow (Picchi, 2003).

Previous studies have addressed the application of VSM in AEC industry, in processes such as design processes (e.g., Lima et al., 2010), house construction (e.g., Yu et al., 2009), drywall and ceramic application (e.g., Bulhões and Picchi 2011), ceramic masonry (e.g., Pasqualini and Zawislak, 2005) and concrete block (e.g., Al-Sudairi, 2007) masonry. However, there are few studies addressing improvements in the processes

1 Graduate Special Student, Graduate program in Civil Engineering, Federal University of Rio Grande do Norte, Natal, RN, Brazil, luane_paiva@hotmail.com

2 Graduate Special Student, Graduate program in Civil Engineering, Federal University of Rio Grande do Norte, Natal, RN, Brazil, victorfclima@gmail.com

3 Assistant Professor, Civil Engineering Dept., Federal University of Rio Grande do Norte, Natal, RN, Brazil, smelo@ct.ufrn.br 
related to the execution of structural masonry through the use of VSM, as the focus is given to VSM measurement parameters (e.g. Ortiz et al., 2012a; Ortiz et al., 2012b).

This paper aims to propose improvements in the structural masonry execution process using VSM to identify wastes and elaborate a future state. This paper's main contribution is the reduction of wastes in the process flow, establishing an ideal situation in a setting where the budget and schedule are not flexible, provoking reflection of scholars and interested in Lean Construction for the application in others projects.

The scope of this paper is restricted to the structural masonry process in one of the seven towers of a residential project, considering the execution of a complete pavement as the batch, from the request of concrete blocks until the completion of the walls elevation. It is restricted to the proposition of a future state and does not include implementation plan. The process mapping considered the concrete blocks as the only material to be analysed.

\section{LITERATURE REVIEW}

\subsection{Lean Thinking}

Womack and Jones define Lean Thinking as a way of combating waste, making more with less effort, equipment, time and space, offering exactly what is desired by customers (1996). Its principles are the specification of value (offering greater added value for the customer), value chain identification (identifying and eliminating waste throughout the activities), flow (production without interruptions), pulled production (production according to demand) and perfection (continuous improvement through rapid detection and solution of problems in their root).

\subsection{Value Stream Mapping}

Value Stream Mapping is a tool that enables the visualization and understanding the material and information flow as the goes through its value flow. In order to obtain the continuous or pulled flow, a proposition of an ideal production chain can be made, getting as close as possible to produce only what customers need and when they need it (Rother and Shook, 2003). The focus is on eliminating wastes and, therefore, increasing the amount of time that effectively adds value to the process.

\section{RESEARCH METHOD}

An exploratory case study was chosen as the research strategy, an empirical investigation that analyse a phenomenon within its contemporary context, in which the researcher has little or no control over the events (Yin, 1994). It was necessary to explore the problems related to the unit of analysis: The execution of structural masonry on a floor, from the arrival of concrete blocks on site to the end of the last block row.

The structural masonry execution process was chosen because it is the most relevant activity in the budget and schedule of the project and, therefore, proposed improvements would generate a significant impact.

The study was carried out in one of the seven 14-storey towers of the project, with eight apartments per pavement. The selected tower was chosen as representative, since it started the services of structural masonry in the sixth floor by the time of data collection. The cycle times collected are an average of the execution's productivity in each tower floor, including the one, which the authors observed the execution. 
The collected data included the triangulation from three sources: administrative documents (productivity, people and material request spreadsheets), 30 minutes unstructured interviews (with two interns, a crane operator, a construction technician, a foreman and a site engineer) and direct observation (measurements of cycle times and wastes). The period of data collection on site was comprised between November 7th and 14th of 2016. The historical data of the worksheets were tracked from the beginning of September until November 15th, 2016. The analysis focused on the identification of wastes and problems in the process, in order to propose improvements.

Construct validity was addressed by comparing the data collected with principles reported in Lean Construction's literature and data triangulation through multiple sources of evidence. With regards to the external validity, an analytic generalization is considered, in which the case study generates theoretical propositions that would be applicable to other contexts.

Rother and Shook proposed five steps to implement Lean Thinking through VSM: Select a family of products, map the current state, analyse the current state, map the future state and elaborate the work and implementation plan (2003). In this study, the authors selected a stage of the productive process of construction instead of selecting a family of products to initiate VSM as suggested by Pasqualini and Zawislak (2005). The selected stage was the execution of structural masonry.

\section{CURRENT STATE MAPPING AND ANALYSIS}

The current state mapping was elaborated with the purpose of applying the principle of the value chain identification, presenting a panoramic view of the stages, from the request of blocks to the last masonry row completion. Information about Cycle Time (CT), inventories, employees involved, problems affecting production and quality problems was collected during all process' stages. A working day containing 8.8 hours was adopted.

The process starts from the blocks request made by the project team, as shown in Figure 1. The construction technician checks the stock of blocks on site every Friday, compares it with the amount needed for the next week according to the bricklayers' productivity and makes the order, adding a safety margin of material sufficient for a week of work (1.5 to 2 pavement inventory per tower, depending on the block typology). The construction technician highlighted that the project team has already faced problems related to block's supplier reliability, such as: delay in block deliveries and dimensional variability not complied with Brazilian standards. As a result, the construction company replaced the blocks' supplier three times. Therefore, the technical team fears to be damaged again, mainly by the lack of material delivery.

One hundred and eighteen pallets of different block typologies are required for the execution of a complete pavement masonry, of which 22, 62 and 34 are, respectively, for the execution of the first, second to ninth and tenth to thirteenth row. Eight munck trucks deliver these pallets with a capacity of 16 pallets each, which supply the work throughout the week. The amount of trucks per day is variable as it depends on the availability of the supplier. 


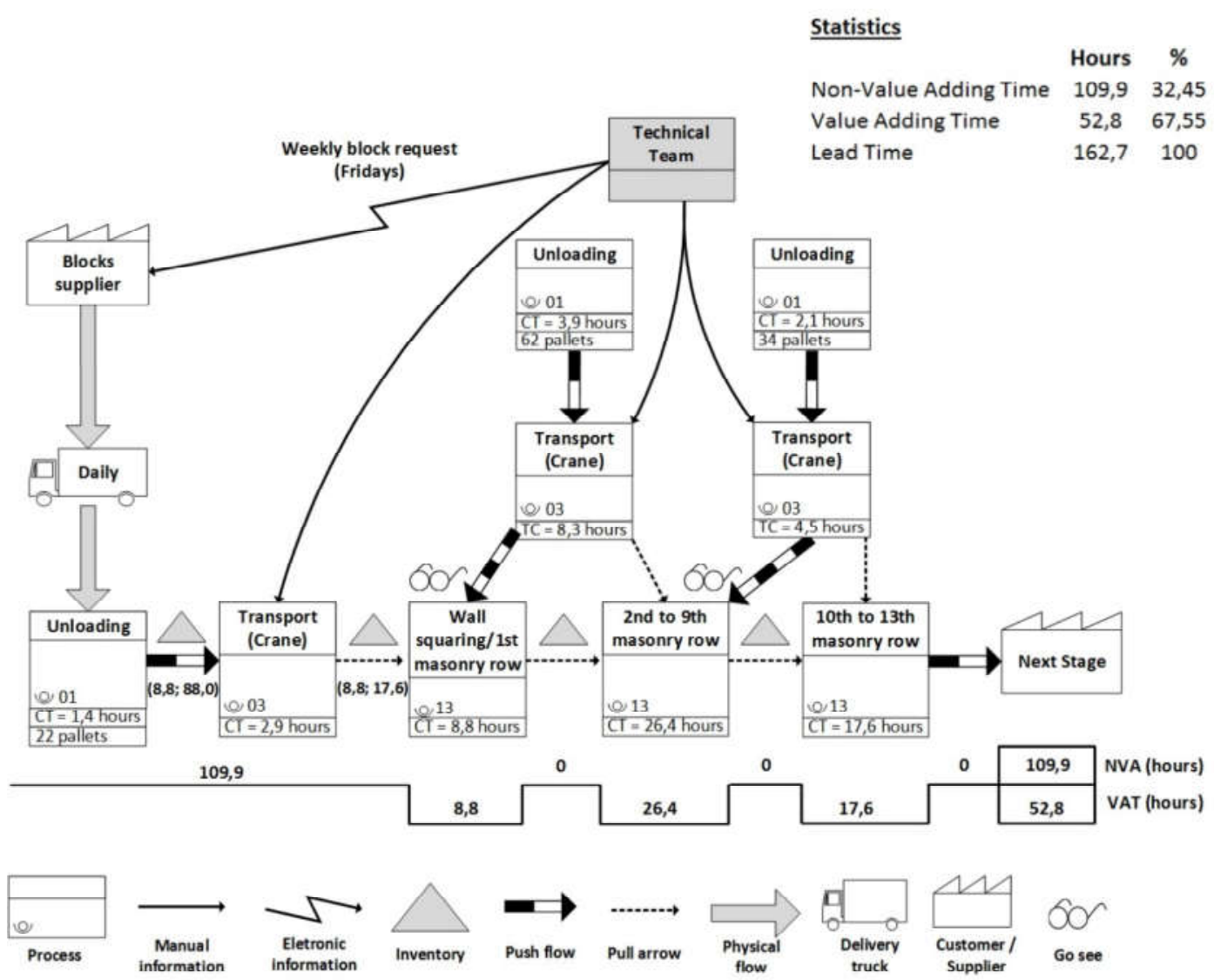

Figure 1: Current state map

After the arrival of trucks in the construction site, the unloading is carried out with the supervision of the stockroom assistant who indicates the place where the materials should be placed. It was observed that the blocks are unloaded where there is access to the trucks and space on site, i.e., there is no standardization or control of where the stock will be. In one hour, the supplier company's workers unload the 16 pallets. Twenty-two pallets are required for the first row of the masonry. For this reason, in the current state mapping the unload time for 22 pallets (1.4 hours) was considered as the initial process. Additional unloading happens simultaneously to the execution of the masonry.

After the block inventory is positioned on site, the vertical transport stage is started with the help of two cranes, which attend the simultaneous construction of seven towers. At this stage, both the production team and the researchers verified a production bottleneck. There was a delay in the blocks supply due to the way information flows to the crane operator, through verbal communication in real time. As a result, there was a decrease in productivity and even a total stoppage of some block laying team, reaching up to a 6-hour wait.

The signalman (the eyes of the crane operator) chooses the pallet that is more accessible to carry out after being informed of the need for material. Therefore, the first blocks that arrive on site are not always the first ones to be transported to the pavement. Therefore, the blocks inventory time on site can vary from one to 10 days, i.e., from 8.8 to 88 hours of work. The crane takes, on average, 8 minutes moving a pallet of blocks to a pavement. This moving time varies according to the positioning of the blocks (unloaded without much criterion) in relation to the crane and the tower. 
The blocks required for the execution of the first masonry row are placed on the pavement, on average, 1 to 2 days before its use (waiting stock of 8.8 to 17.6 hours of work); because block layers fear that, the crane will not attend their real-time supply needs. Next, the step of wall squaring and first row execution is realized in the whole pavement (external and internal masonry). Through direct observation it was even found that there was not enough blocks on the pavement for this first stage, which is why the workers slowed down until the crane could continue with the supply.

During the execution of the first row, when the time is available, the crane transports blocks for the second to the ninth row to the pavement, exceeding the working hours.

The intern checks the walls' first row as the workers complete the rooms' walls of the apartments, i.e., this service is simultaneous to the elevation of the first row. The other rows' elevation is executed simultaneously to the supply of blocks by the crane. The blocks' supply is realized when time is available, as that two cranes are responsible for the supply of several materials for the seven towers.

It was observed that the masonry execution sequence in the pavement is variable, i.e., in some pavements, the masonry of the four apartments on one side is executed first, and then the elevation of the others is done. In other floors, the masonry of all apartments is executed simultaneously. There is, in this case, an opportunity for improvement related to the standardization of work.

From the collected data, it can be observed that lead-time (time from the start to the end of the process) is 162.7 hours, 109.9 hours (67.55\%) of Non-Value Adding Time (NVA) and 52.8 hours $(32.45 \%)$ of Value Adding Time (VAT). The slab formwork assembling follows the masonry elevation completion.

\section{FUTURE STATE MAPPING}

During the data collection and analysis process, it became evident that the unloading of blocks and their transportation through the crane was generating a lot of waste of time and space. It was also contributing to the instability and uncertainty of the production. The project team also reported that this was the main source of problems on site.

With regards to the storage of blocks, the inventory waste reported by Ohno (1988) was identified, as the weekly order is made by adding a safety margin of material for a week of work. As a consequence, there is a material idleness for a period of up to 10 days, quality problems omission and delays related to the difficulty of transportation by the crane. The possibility of applying the principle of pull production was observed, reducing this safety margin to the equivalent of three working days as an initial attempt. For now, there is still insufficient trust in the supplier to order for only what is needed.

In this context, the use of a supermarket system was proposed (Figure 2). This type of solution is recommended for processes where it is not possible to produce directly in a continuous flow, that is, the delivery of one piece at a time is not realistic (Rother and Shook, 2003). The quantity of pallets to be ordered is communicated to the project team as the production pulls its consumption. This supermarket system eliminates the need for the construction technician to check personally all available inventories so that he can estimate the order to be made for the week, which eliminates the unnecessary movement waste. 


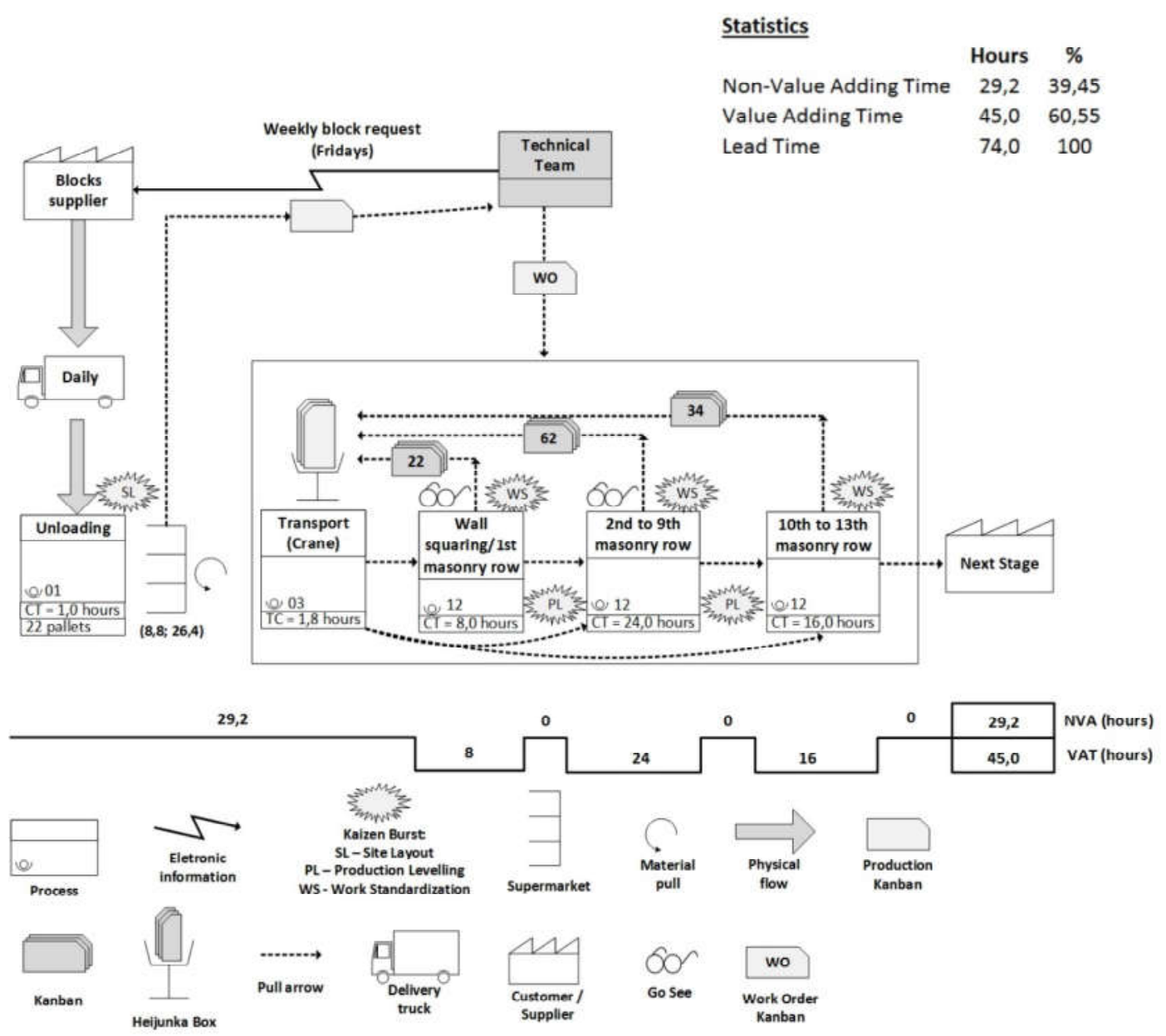

Figure 2: Future state map

With regards to the transportation stage, it is known that this is a necessary activity, but does not add value, as it is also one of the wastes reported by Ohno (1988). To reduce this waste, one of the recommendations is the reorganization of the site's layout (Rich and Hines, 1997). Therefore, the principle of perfection can be applied through an improvement in the construction site's layout, with the purpose of organizing the supermarket inventory by block typologies, sequence of delivery and proximity to the tower. This can reduce the cycle time of unloading, add value for the crane operator and his team and establish a flow, providing better transport conditions (a reduction of the crane TC is estimated for 5 minutes) and avoiding waiting of blocks on the pavement.

In the future state the crane could no longer operate through verbal communication in real time, but through a kanban system, previously placed in a heijunka box, a board that stores these cards which could be fixed to the base of the crane. The kanban system can be used by the production team to request the quantity, type, destination and delivery time of the pallets. In order to no longer have to make decisions about the urgency or priority of transport, the crane's signalmans would now meet the demand that is previously defined in the heijunka box (creating a pull production).

The masonry execution in the pavement starts from the request of production (kanban) delivered by the project team as work orders. This kanbans would contain 
information about the pavement to be executed, due time, workers team and worker's payment.

Based on the principle of perfection (continuous improvement), production levelling and work standardization are proposed through block layers' training and use of pokayoke tools.

By contacting the blocks supplier, it is proposed that previously cutted blocks are sent to the construction site in pallets. These blocks are used in several points of the walls for the fixation of the reinforcement and later the grouting. As a result, improved productivity can be achieved by reducing unnecessary movement wastes on the pavement, waiting time for cutting and reducing the production team by eliminating the cutter (a worker that only cuts blocks). An improvement of about $10 \%$ in the cycle time of the productive stages is estimated.

Through the proposed improvements, it is estimated that lead time will be reduced in 45.5\%, from 162.7 to 74.0 hours, 45.0 hours (60.55\%) of Non-Value Adding Time (NVA) and 29.2 hours $(39,45 \%)$ of Value Adding Time (VAT). The main contribution in the reduction of time is the reduction of stock's idle time on site. With the mitigation of identified wastes, the masonry process presented a Value Adding Time that is expressively superior to the current state one, leading from $32,45 \%$ to $60,55 \%$.

\section{CONCLUDING REMARKS}

Using VSM in the structural masonry process, this paper contributes to the literature on several fronts. First, it establish a future state that provides better conditions for the company. Second, it awakens the reflection of academics and practitioners for application in other contexts within the structural masonry construction system. Third, the use of VSM provided a systemic view of the concrete block supply chain, facilitating the identification of wastes and their origin, from the request of material to the execution of the last masonry row. Wastes related to excess inventory, material transportation, information flow, unnecessary movements, variability in team productivity and in the way of performing the pavement were identified.

The main proposed improvements are as follows: the reduction of block inventory, reorganization of the layout concerning the storage of blocks, the use of a kanban system to improve the crane information flow, supply of cutted blocks, work standardization and production levelling.

Concerning improvements implementation, an important issue is the awareness of the team. After that, future state map implementation could start with its division into pull loop and additional loops, as recommended by Rother and Shook (2003). The pull loop should be the first one to be improved, as its activities impact the previous loops. Masonry execution pulls the transport and request of blocks in the analysed process. Therefore, work standardization in the block laying process can be the first implementation effort. Then, production levelling should be easier. Thereafter, the times when blocks are needed are clearer, block inventory is possible to be reduced, layout can be reorganized and heijunka box can be implemented.

One limitation of this study is that the authors did not include the upstream supply chain stages in the analysis. Future studies should address the following: an analysis of the relationship between the construction company and the block supplier; block supplier internal processes and the cutted blocks supply. A more effective reduction of inventories requires commitment and a trust relationship with the supplier, leading to 
the elimination of wastes. Moreover, future studies may include an implementation plan and feasibility tests for the proposed improvements.

\section{ACKNOWLEDGMENTS}

The authors would like to thank the company that provided data for this study.

\section{REFERENCES}

Al-Sudairi, A. A. (2007). Evaluating the effect of construction process characteristics to the applicability of lean principles. Construction Innovation. 7(1), pp. 99-121.

Bulhões, I. R. and Picchi, F. A. (2011). Diretrizes para a implementação de fluxo contínuo em obras de edificações. Ambiente construído, 11(4), pp. 205-223.

Hines, P. and Rich, N. (2005). The Seven value stream mapping tools. International Journal of Operations \& Production Management. 17(1), pp. 46-64.

Koskela, L. (1992). Application of the New Production Philosophy to Construction. Technical Rep. No. 72, Center for Integrated Facility Engineering, Dept. of Civil Engineering, Stanford University, Stanford, Calif.

Lima, M., Rolim, L. and Alves, T.D.C. (2010), Value stream mapping of the architectural executive design in a governmental organization" In: Walsh, K. \& Alves, T., 18th Annual Conference of the International Group for Lean Construction. Haifa, Israel, 14-16 Jul 2010. pp 415-424

Ohno, T. (1988). Toyota Production System: Beyond large-scale production. New York: Productivity Press.

Ortiz, F. H.; Vivan, A. L.; Paliari, J. C. (2012a). Parâmetros de eficácia na aplicação de ferramentas lean a partir da análise do mapeamento do fluxo de valor. In: 14th Encontro Nacional de Tecnologia do Ambiente Construído. Juiz de Fora. [Acessed 16 nov 2016]. Available from: http://www.infohab.org.br/entac2014/2012.php.

Ortiz, F. H.; Vivan, A. L.; Paliari, J. C. (2012b). Mapeamento do fluxo de valor: adaptações e inclusões de novas informações visando potencializar suas vantagens para a construção civil. In: 14th Encontro Nacional de Tecnologia do Ambiente Construído. Juiz de Fora. [Acessed 16 nov 2016]. Available from:

http://www.infohab.org.br/entac2014/2012.php.

Pasqualini, F. and Zawislak, P.A. (2005). Value stream mapping in construction: A case study in a Brazilian construction company. In: 13th Annual Conference of the International Group for Lean Construction. Sydney, Australia, 19-21 Jul 2005. pp 117-125.

Picchi, A.F. (2003). Oportunidades da aplicação do lean thinking na construção. Ambiente Construído. 4(1), pp.7-23.

Rother, M. and Shook, J. (2003) Learning to see: Value stream mapping to create value and eliminate muda. The Lean Enterprise Institute, Cambridge, MA. Version 1.3., June 2003.

Womack, J. P. and Jones D. T. (1996). Lean thinking: Banish waste and create wealth in your corporation, Simon and Schuster, New York.

Yin, R. K. (1994). Case study research: Design and methods. Thousand Oaks, CA: Sage.

Yu, H.; Tweed, T.; Nasseri, R. (2009). Development of lean model for house construction using value stream mapping. Journal of construction engineering and management. 135(8), pp. 782-790. 